\title{
Ganho genético avaliado com índices de seleção e com REML/Blup em milho-pipoca
}

\author{
Ismael Lourenço de Jesus Freitas ${ }^{(1)}$, Antonio Teixeira do Amaral Junior(1), Alexandre Pio Viana(1), \\ Guilherme Ferreira Pena(1), Pablo da Silva Cabral ${ }^{(1)}$, Cássio Vittorazzi ${ }^{(1)}$ \\ e Thiago Rodrigues da Conceição Silva(1)
}

\begin{abstract}
(1)Universidade Estadual do Norte Fluminense Darcy Ribeiro, Avenida Alberto Lamego, o 2.000, Parque Califórnia, CEP 28013-602 Campos dos Goytacazes, RJ, Brasil. E-mail: ismaellj@yahoo.com.br, amaral@uenf.br, pirapora@uenf.br, penabio@yahoo.com.br, pablodscabral@hotmail.com, vittorazzicastelo@yahoo.com.br, thiagrosfi@yahoo.com.br
\end{abstract}

Resumo - O objetivo deste trabalho foi comparar quatro índices de seleção e o método REML/Blup na avaliação de ganhos genéticos preditos das características de interesse ao programa de melhoramento do milho-pipoca UENF 14. Foram avaliadas 200 progênies de irmãos-completos, em uma safra, em dois ambientes (regiões Norte e Noroeste do Estado do Rio de Janeiro), com duas repetições, o que totalizou 800 observações. Avaliaram-se as características altura média de plantas, altura média de inserção da primeira espiga, estande final, tombamento, diâmetro de colmo, prolificidade, rendimento e capacidade de expansão dos grãos. Entre os índices de seleção testados, o de Mulamba \& Mock proporcionou os melhores resultados para a seleção das progênies de irmãos-completos. O método REML/Blup mostrou-se muito eficiente, tendo selecionado progênies com desempenhos relativos elevados e com ganhos genéticos preditos melhores que os dos índices de seleção testados. As progênies selecionadas com uso do método REML/Blup, para maior rendimento de grãos, não são as mesmas selecionadas para maior capacidade de expansão. $\mathrm{O}$ índice de Mulamba \& Mock e o método REML/Blup proporcionam os melhores ganhos preditos para a população UENF 14.

Termos para indexação: Zea mays, correlação genética, modelos mistos, seleção recorrente, seleção simultânea.

\section{Genetic gain evaluated with selection indices and with REML/Blup in popcorn}

\begin{abstract}
The objective of this work was to compare four selection indices and the REML/Blup method in the evaluation of the predicted genetic gains for the characteristics of interest to the breeding program of the UENF 14 popcorn. Two hundred full-sib progenies were evaluated in one season, in two locations (North and Northwest Regions of the state of Rio de Janeiro, Brazil), with two replicates, totaling 800 observations. The characteristics evaluated were average plant height, average height of first ear insertion, final stand, tipping, stem diameter, prolificacy, grain yield and popping expansion. Among the selection indices tested, Mulamba \& Mock's provided the best results for selection of full-sib progenies. The REML/Blup method proved to be very efficient, selecting progenies with high relative performance and better predicted genetic gains than those of the selection indices tested. The progenies selected using the REML/Blup method, for highest grain yield, are not the same as those selected for higher popping expansion. The Mulamba \& Mock index and the REML/ Blup method provide the best predicted gains for the UENF 14 population.
\end{abstract}

Index terms: Zea mays, genetic correlation, mixed models, recurrent selection, simultaneous selection.

\section{Introdução}

O milho-pipoca (Zea mays L.) é considerado uma cultura de elevada rentabilidade entre os denominados "milhos especiais", com influência positiva em setores da economia nacional. No entanto, sua área de plantio comercial é insuficiente para atender o mercado nacional (Moterle et al., 2011; Pena et al., 2012; Ribeiro et al., 2012; Vittorazzi et al., 2013).

De acordo com Freitas Júnior et al. (2009), para atender ao consumo interno de milho-pipoca, era necessário importar grãos, sobretudo dos Estados Unidos da América e da Argentina. Entretanto, mudanças no mercado têm ocorrido e, com o uso em larga escala de híbridos nacionais e norte-americanos, ocorreu grande redução na importação de grãos (Rangel et al., 2008).

Em 2013, foram cultivados 43.379 mil hectares, e a previsão é produzir 171.111 mil toneladas do grão. Em comparação ao ano anterior, houve uma expansão de $64,58 \%$ na área plantada e um crescimento de $67,39 \%$ do volume colhido. Em 2012, foram ocupados 
26.356 mil hectares com milho-pipoca e colhidas 102.221 mil toneladas (Levantamento Sistemático da Produção Agrícola, 2013). Apesar disso, há carência de cultivares de milho-pipoca no mercado de cereais com características agronômicas desejáveis; portanto, é necessário intensificar o lançamento de variedades e híbridos comerciais (Rangel et al., 2011).

Desde 1998, o programa de melhoramento genético do milho-pipoca, conduzido pela Universidade Estadual do Norte Fluminense Darcy Ribeiro (UENF), tem obtido ganhos genéticos expressivos para a cultura, principalmente quanto às duas principais características: rendimento e capacidade de expansão dos grãos.

A variedade de polinização aberta UENF 14 referese ao ciclo C6 de seleção recorrente em UNB-2U. UNB-2U, por sua vez, originou-se de dois ciclos de seleção massal de UNB-2, em Campos dos Goytacazes, RJ. A população UNB-2 é resultante de seleção em um composto indígena doado à Universidade de Brasília (UnB), DF, pela Esalq/USP. Desse procedimento, obteve-se a população UNB-1, a qual foi cruzada com a variedade de milho-pipoca Americana. As progênies do referido cruzamento foram selecionadas e cruzadas com uma variedade de milho-pipoca de grãos amarelos e com resistência a Exserohilum turcicum (helmintosporiose). Decorridos dois ciclos de seleção massal, a população obtida apresentava resistência, produtividade superior e grãos amarelos. Após três retrocruzamentos com a variedade Americana, foi obtida a população UNB-2U, de polinização aberta (Pereira \& Amaral Júnior, 2001).

Em milho-pipoca, a correlação negativa entre as duas principais características de valor econômico - capacidade de expansão e produtividade de grãos - dificulta a seleção de genótipos de interesse para o melhoramento e torna necessário o emprego de procedimentos genético-estatísticos que permitam minimizar os efeitos deletérios da resposta correlacionada (Daros et al., 2004). Para tanto, os índices de seleção são procedimentos indispensáveis, pois permitem obter ganhos simultâneos mesmo para características com efeitos adversos, que podem ter origem na ligação gênica ou na pleiotropia (Rangel et al., 2011).

Os índices de seleção permitem gerar um agregado genotípico sobre o qual se exerce a seleção e que funciona como caráter adicional, resultante da combinação de determinadas características escolhidas pelo melhorista, nas quais se deseja exercer a seleção simultânea. Dessa forma, é possível separar genótipos superiores para um conjunto de caracteres, independentemente da existência ou não de correlações entre características (Vilarinho et al., 2003; Amaral Júnior et al., 2010; Cruz et al., 2012).

A realização de inferências sobre materiais, em fase de lançamento de cultivares, deve recair sobre os verdadeiros valores genotípicos, ou seja, basearem-se em médias genotípicas e não fenotípicas (Borges et al., 2010). Segundo Resende (2001), a estruturação dos procedimentos de seleção, os quais são responsáveis pelo sucesso dos programas de melhoramento genético, baseia-se na estimação dos componentes de variância e na predição dos valores genéticos dos candidatos à seleção. Uma alternativa muito utilizada atualmente e com grande acurácia no processo seletivo é o emprego de componentes de variância estimados por máxima verossimilhança restrita (REML) e por valores genéticos ou genotípicos preditos pelo melhor preditor linear não viciado (Blup) (Rodrigues et al., 2013). Embora este método ainda seja pouco utilizado em plantas anuais, tem mostrado grande potencial para progressos genéticos de maior relevância.

O objetivo deste trabalho foi comparar quatro índices de seleção e o método REML/Blup na avaliação de ganhos genéticos preditos das características de interesse ao programa de melhoramento do milho-pipoca UENF 14.

\section{Material e Métodos}

A variedade utilizada foi a UENF 14, de polinização aberta, referente ao ciclo $\mathrm{C} 6$ de seleção recorrente em UNB-2U. O método utilizado para a obtenção das progênies foi a seleção recorrente entre progênies de irmãos-completos. Foram semeadas 200 linhas compostas da mistura das sementes recombinadas do sexto ciclo de seleção recorrente em UENF 14. Enumeraram-se as fileiras e as plantas de cada fileira para facilitar a identificação dos cruzamentos que foram feitos aos pares. As espigas foram cobertas com sacolas de plástico antes de liberarem os estilo-estigmas, para evitar contaminação. Esse procedimento foi realizado no Colégio Estadual Agrícola Antônio Sarlo, situado no Município de Campos dos Goytacazes, RJ (21 $\left.42^{\prime} 49^{\prime \prime} \mathrm{S}, 41^{\circ} 20^{\prime} 33^{\prime \prime W}\right)$. Foram utilizadas linhas de

Pesq. agropec. bras., Brasília, v.48, n.11, p.1464-1471, nov. 2013 DOI: $10.1590 / \mathrm{S} 0100-204 X 2013001100007$ 
5,0 $\mathrm{m}$ de comprimento, com espaçamento de $0,90 \mathrm{~m}$ entre linhas, cada uma com 25 plantas, no espaçamento de $0,20 \mathrm{~m}$ na linha. Utilizaram-se três sementes por cova, à profundidade de $0,05 \mathrm{~m}$. Aos 21 dias após a emergência, realizou-se o desbaste, tendo-se deixado uma planta por cova. Deste procedimento, foram obtidas 200 progênies com duas espigas de irmãos-completos de cada progênie.

Os plantios para a avaliação das 200 progênies foram realizados em outubro de 2011 na Estação Experimental da Pesagro, na Ilha do Pomba, em Itaocara, RJ (2140'09"S, 4204'34"W), e no Colégio Estadual Agrícola Antônio Sarlo, em Campos dos Goytacazes, RJ. Utilizou-se o delineamento experimental de blocos ao acaso, em arranjo em "sets", que são grupos de tratamentos utilizados para reduzir a área experimental e aumentar a precisão do experimento. Foram utilizados oito "sets" com duas repetições, em que cada "set" conteve 25 progênies de irmãos-completos. Utilizaram-se linhas de $5,0 \mathrm{~m}$ de comprimento, com espaçamento de $0,90 \mathrm{~m}$ entre linhas, cada uma com 25 plantas, no espaçamento de $0,20 \mathrm{~m}$ na linha. Foram utilizadas três sementes por cova, à profundidade de $0,05 \mathrm{~m}$. Aos 21 dias após a emergência, foi realizado o desbaste, tendo-se deixado uma planta por cova, o que totalizou uma população de 55.555 plantas por hectare. Os tratos culturais foram realizados sempre que necessário, de acordo com as recomendações para a cultura (Fancelli \& Dourado Neto, 2000).

As características avaliadas foram: altura média de plantas (AP), em cm; altura média de inserção da primeira espiga (AE), em cm; estande final (NP), expresso pelo número médio de plantas por fileira; tombamento, expresso pelo número de plantas acamadas e quebradas; diâmetro de colmo, em mm; prolificidade, que se refere ao número médio de espigas por planta; rendimento de grãos (RG), em kg ha-1; e capacidade de expansão dos grãos $(\mathrm{CE})$, em $\mathrm{mL} \mathrm{g}^{-1}$.

Foram testados os índices de seleção de Smith (1936), Hazel (1943), Williams (1962) Pešek \& Baker (1969) e Mulamba \& Mock (1978) para seleção das 30 progênies superiores. Nas análises computacionais, foram atribuídos pesos econômicos, por tentativas (14, $14,2,5,2,5,2,5,20,35$ e 40), para cada característica analisada. A seleção das progênies superiores com base em índices de seleção foi realizada com uso dos recursos computacionais do programa Genes (Cruz, 2013).

As avaliações fenotípicas foram realizadas com o programa Selegen-REML/Blup, com o modelo estatístico 148 (vários locais e uma safra, em blocos completos):

$$
\mathrm{Y}=\mathrm{Xr}+\mathrm{Zg}+\mathrm{Wp}+\mathrm{Ti}+\varepsilon
$$

em que Y é o vetor de valores fenotípicos; $r$ é o vetor dos efeitos de repetição (assumidos como fixos) somados à média geral; g é o vetor de valores genotípicos individuais (assumidos como aleatórios); $\mathrm{p}$ é o vetor dos efeitos de parcela (assumidos como aleatórios); i é o vetor dos efeitos da interação genótipo $\mathrm{x}$ ambiente (aleatórios); $\varepsilon$ e é o vetor de erros ou resíduos (aleatórios). As letras maiúsculas representam as matrizes de incidência para os referidos efeitos. $\mathrm{O}$ vetor $\mathrm{r}$ contempla todas as repetições de todos os locais (ajusta as combinações repetição-local). Nesse caso, esse vetor inclui os efeitos de locais e de repetição dentro de locais.

Os valores genéticos de cada família foram obtidos pela soma de cada efeito genotípico $(\mathrm{g})$ à média geral do experimento $(\mathrm{u})$. $\mathrm{O}$ ganho genético equivale à média dos vetores dos efeitos genéticos preditos para as progênies selecionadas. A média geral somada ao ganho genético resulta na média da população melhorada. O desempenho relativo (DR) de cada família foi obtido pela relação entre as médias da população melhorada de cada família e a média da família de maior valor genético.

O índice de coincidência foi obtido por meio da relação entre o dobro do número de progênies, em que ambos os índices de seleção coincidem, e a soma do número total de progênies que contém o índice de seleção A mais o número total de progênies que contém a índice de seleção B (Pedrozo et al., 2009).

\section{Resultados e Discussão}

O índice de Pesek \& Baker resultou em ganhos indesejáveis para $\mathrm{AP}$ e $\mathrm{AE}$, de 2,1 e 2,95\%, respectivamente (Tabela 1); portanto, esse índice não é indicado, pois plantas com portes maiores e com espigas mais altas dificultam a colheita, além de serem mais susceptíveis ao quebramento e ao acamamento, em regiões como o Norte e o Noroeste Fluminense, que apresentam elevada incidência de ventos. 
A altura de planta extrema e a alta proporção entre altura de plantas e altura de espigas podem tornar a cultivar mais suscetível ao acamamento e, consequentemente, não recomendada para o cultivo em locais com grande intensidade de ventos e com solos férteis, que fazem com que a planta cresça em demasia (Miranda et al., 2003).

O índice de Smith \& Hazel apresentou ganho genético predito elevado para $\mathrm{CE}$, com valor médio de $7,4 \%$. Embora tenha ocorrido ganho positivo para rendimento de grãos, este foi baixo $(2,19 \%)$. Diferenças entre valores de ganhos genéticos preditos para RG e CE, pelo índice de Smith \& Hazel, por diferentes pesos econômicos, também foram observadas por Santos et al. (2008), Freitas Júnior et al. (2009) e Rangel et al. (2011), em ciclos anteriores da população avaliada no presente trabalho. Contudo, esses resultados não permitem afirmar que o índice de Smith \& Hazel não seja adequado para a seleção de progênies na referida população. Berilli et al. (2011) também utilizaram o índice de Smith \& Hazel, em programa de seleção recorrente em progênies de irmãos-completos, em milho comum, e obtiveram ganho de $14,26 \%$ quanto ao rendimento de grãos.

As características AP e AE, avaliadas pelo índice de Mulamba \& Mock, apresentaram valores baixos, de 0,66 e $0,32 \%$, respectivamente (Tabela 1 ), o que é desejável, pois plantas de porte alto e com espigas mais elevadas tendem ao tombamento, características que apresentaram ganhos negativos de $-1,37 \%$. Ao

Tabela 1. Estimativas dos ganhos percentuais com base no diferencial de seleção, por seleção simultânea em oito características, no sétimo ciclo de seleção recorrente intrapopulacional, em progênies de irmãos-completos de milho-pipoca UENF 14.

\begin{tabular}{lrrrrr}
\hline Característica $^{(1)}$ & \multicolumn{4}{c}{ Índices de seleção } & REML/ \\
\cline { 2 - 4 } & $\begin{array}{c}\text { Pesek \& } \\
\text { Baker }\end{array}$ & $\begin{array}{c}\text { Smith \& } \\
\text { Hazel }\end{array}$ & $\begin{array}{c}\text { Mulamba } \\
\text { \& Mock }\end{array}$ & Williams & \\
\hline AP & 2,10 & 2,03 & 0,66 & 2,27 & 0,69 \\
AE & 2,95 & 2,79 & 0,32 & 3,28 & 0,92 \\
Estande final & 0,77 & 0,58 & 1,04 & 1,24 & 8,70 \\
Tombamento & $-2,97$ & $-3,21$ & $-1,37$ & $-1,71$ & 1,81 \\
Diâmetro & 1,17 & 1,24 & 1,32 & 1,54 & 13,39 \\
Prolificidade & 1,59 & 1,11 & 3,24 & 2,65 & 17,41 \\
RG & 3,33 & 2,19 & 7,78 & 16,02 & 33,06 \\
CE & 7,33 & 7,40 & 5,11 & $-1,68$ & 13,08 \\
\hline
\end{tabular}

${ }^{(1)} \mathrm{AP}$, altura média de plantas; AE, altura média de inserção da primeira espiga; RG, rendimento de grãos; $\mathrm{CE}$, capacidade de expansão dos grãos. contrário, com o índice de seleção de Williams, foram obtidos ganhos relativos para as características AP e $\mathrm{AE}$, o que mostra que este não é indicado para seleção, uma vez que essas características não são desejáveis nas regiões Norte e Noroeste Fluminense.

De acordo com o método REML/Blup, as características AP e AE apresentaram valores baixos, de 0,69 e $0,92 \%$, respectivamente, o que é desejável. Acaracterística tombamento apresentou baixo valor por este método de $1,81 \%$. Além disso, houve incremento significativo quanto ao diâmetro, de $13,39 \%$, o que é interessante, já que proporciona menor número de plantas quebradas e acamadas (Tabela 1). A qualidade de colmo é uma das mais importantes características do milho-pipoca para a produção em larga escala, com colheita mecanizada. A qualidade do colmo pode ser avaliada pela percentagem das plantas acamadas e quebradas (Miranda et al., 2003).

No melhoramento do milho-pipoca, as principais características de interesse são a capacidade de expansão e o rendimento de grãos (Silva et al., 2013). Ao se comparar os índices de seleção ao $\mathrm{RG}$ e à $\mathrm{CE}$, observa-se que, apesar da correlação negativa entre essas duas características, houve ganhos para todos os índices testados, com exceção do índice de seleção de Williams, o qual foi de $16,02 \%$, para RG, e de $-1,68 \%$ para CE (Figura 1). Ao analisar a viabilidade do uso do índice de seleção de Williams em milho-pipoca, Granate et al. (2002) concluíram que este não possibilitou a obtenção de estimativas de ganhos preditos simultâneos nas características de interesse RG e CE, o que está de acordo com o presente trabalho.

Os ganhos percentuais preditos para o índice de seleção de Mulamba \& Mock proporcionaram valores simultâneos mais elevados relativos ao $\mathrm{RG}$ e à $\mathrm{CE}$, de 7,78 e 5,11\%, respectivamente (Figura 1). Assim, essas progênies apresentaram elevada média para capacidade de expansão e rendimento de grãos. Entre os índices testados, o de Mulamba \& Mock foi o que apresentou os melhores resultados para a seleção das progênies de irmãos-completos, não apenas por proporcionar ganhos satisfatórios quanto à $\mathrm{CE}$ e ao RG, mas, também, por revelar ganhos negativos para características indesejáveis ao melhoramento do milho-pipoca.

Diferenças entre os ganhos genéticos preditos para RG e CE pelo índice de Mulamba \& Mock, por diferentes pesos econômicos, também foram relatadas por Santos et al. (2008), Freitas Júnior et al. (2009), 
Rangel et al. (2011) e Ribeiro et al. (2012), em ciclos anteriores da população UENF 14. Com esses resultados, pode-se afirmar que o índice de Mulamba \& Mock é adequado para a seleção de progênies na referida população.

Quanto ao método REML/Blup, obteve-se melhoria simultânea das características CE e RG (Tabela 1). Constatou-se elevado valor tanto em relação ao RG quanto à $\mathrm{CE}$, de 33,06 e 13,08\%, respectivamente, superior a todos os índices de seleção testados. Quando comparado ao índice de seleção de Mulamba \& Mock, verificou-se diferença de ganho de $25,28 \%$, para $R G$, e de $7,95 \%$ para CE. Essa diferença pode ser explicada pelo fato de o método REML/Blup utilizar, como vetor de soluções, os efeitos genotípicos preditos e os ganhos de seleção para cada família, o que corrige os valores para os efeitos ambientais, prediz de maneira precisa e não viciada os valores genotípicos, e conduz à maximização do ganho genético com a seleção (Resende \& Sturion, 2001; Rodrigues et al., 2013). Arnhold et al. (2009) avaliaram híbridos de milho-pipoca pelo método REML/Blup e identificaram genótipos de milho-pipoca com melhor rendimento e capacidade de expansão dos grãos.

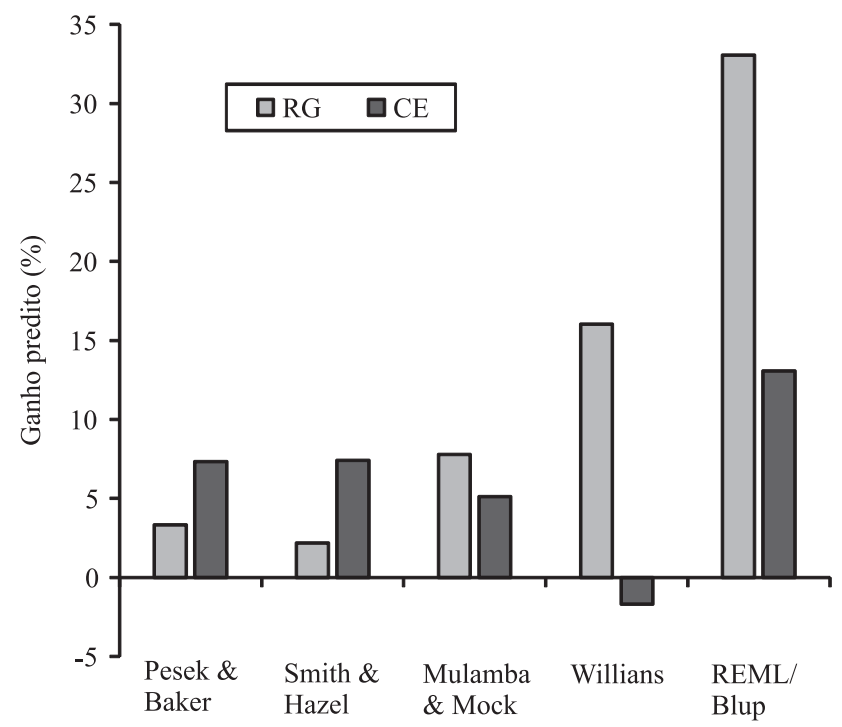

Figura 1. Estimativas dos ganhos percentuais preditos, com base nos índices de seleção de Pesek \& Baker, Smith \& Hazel, Mulamba \& Mock e de Williams e no método REML/Blup, por seleção simultânea de rendimento de grãos (RG) e capacidade de expansão dos grãos (CE), no sétimo ciclo de seleção recorrente intrapopulacional, em progênies de irmãos-completos de milho-pipoca UENF 14.
De acordo com Pedrozo et al. (2009), quanto maior o coeficiente de coincidência entre dois índices de seleção, maior será a concordância dos resultados de seleção entre eles. Os coeficientes de coincidência das 30 progênies de irmãos-completos selecionados pelos índices Pesek \& Baker, Smith \& Hazel, Mulamba \& Mock e Williams, bem como pelo método REML/Blup foram, em geral, baixos, com exceção dos coeficientes encontrados entre os índices de Pesek \& Baker e Mulamba \& Mock, os quais apresentaram valor 1, ou seja, as 30 progênies selecionadas foram as mesmas tanto para CE quanto para RG (Tabela 2).

Ao se comparar os índices de seleção com o método REML/Blup, os maiores coeficientes de coincidência de progênies selecionadas foram obtidos com o índice de Williams: de $0,97 \%$, para $\mathrm{RG}$, e de $0,06 \%$ para $\mathrm{CE}$ (Tabela 2). Esse resultado pode ser explicado pelo fato de a metodologia REML/Blup utilizar, como vetor de soluções, os efeitos genotípicos preditos e os ganhos de seleção para cada indivíduo, o que seleciona grupos diferentes para RG e CE e comprova a correlação negativa entre estas características. No entanto, o índice de Williams não requer estimativas dos parâmetros genotípicos e fenotípicos e utiliza os valores econômicos relativos como coeficientes do índice, o que permite a seleção por meio das características simultâneas (La Gioia, 2006).

No método REML/Blup, as estimativas da média geral (u) do experimento, obtidas para $\mathrm{RG}$ e $\mathrm{CE}$, foram de $3.072,86 \mathrm{~kg} \mathrm{ha}^{-1}$ e $33,16 \mathrm{~mL} \mathrm{~g}^{-1}$, respectivamente. $\mathrm{O}$ desempenho relativo das progênies foi alto, em que todas as 30 progênies selecionadas apresentaram estimativas acima de $80 \%$, tanto para $\mathrm{RG}$ quanto para $\mathrm{CE}$, o que é evidência da acurácia seletiva da metodologia REML/Blup (Tabela 3).

Tabela 2. Coeficientes de coincidência de 30 progênies selecionadas com uso dos índices de seleção e do método REML/Blup, quanto às características rendimento de grãos ( $\mathrm{kg} \mathrm{ha}^{-1}$ ) acima da diagonal e capacidade de expansão dos grãos $\left(\mathrm{mL} \mathrm{g}^{-1}\right)$ abaixo da diagonal, em milho-pipoca UENF 14.

\begin{tabular}{lccccc}
\hline $\begin{array}{l}\text { Índice de } \\
\text { seleção }\end{array}$ & $\begin{array}{c}\text { Pesek \& } \\
\text { Baker }\end{array}$ & $\begin{array}{c}\text { Smith \& } \\
\text { Hazel }\end{array}$ & $\begin{array}{c}\text { Mulamba } \\
\text { \& Mock }\end{array}$ & Williams & $\begin{array}{c}\text { REML/ } \\
\text { Blup }\end{array}$ \\
\hline Pesek \& Baker & - & 0,47 & 1,00 & 0,33 & 0,33 \\
Smith \& Hazel & 0,47 & - & 0,47 & 0,17 & 0,13 \\
Mulamba \& Mock & 1,00 & 0,47 & - & 0,36 & 0,33 \\
Williams & 0,33 & 0,17 & 0,36 & - & 0,97 \\
REML/Blup & 0,43 & 0,67 & 0,43 & 0,06 & - \\
\hline
\end{tabular}


Tabela 3. Ranqueamento e estimativas das 30 progênies superiores de irmãos-completos, dos valores genotípicos previstos $(\mathrm{g})$, dos valores genotípicos $(\mathrm{u}+\mathrm{g})$, da nova média predita (Blup) e do desempenho relativo (DR), quanto às características rendimento e capacidade de expansão dos grãos, em milho-pipoca UENF 14.

\begin{tabular}{|c|c|c|c|c|c|c|c|c|c|c|c|c|}
\hline \multirow[t]{2}{*}{ Ranque } & \multicolumn{6}{|c|}{ Rendimento de grãos $\left(\mathrm{kg} \mathrm{ha}^{-1}\right)$} & \multicolumn{6}{|c|}{ Capacidade de expansão dos grãos $\left(\mathrm{mL} \mathrm{g}^{-1}\right)$} \\
\hline & Família & $\mathrm{g}$ & $\mathrm{u}+\mathrm{g}$ & Ganho & Nova média & DR $(\%)$ & Família & $\mathrm{g}$ & $\mathrm{u}+\mathrm{g}$ & Ganho & Nova média & DR $(\%)$ \\
\hline 1 & 54 & $1.483,93$ & $4.556,79$ & $1.483,93$ & $4.556,79$ & 100,00 & 139 & 5,29 & 38,45 & 5,29 & 38,45 & 100,00 \\
\hline 2 & 196 & $1.464,24$ & $4.537,10$ & $1.474,09$ & $4.546,95$ & 99,78 & 154 & 4,72 & 37,88 & 5,01 & 38,17 & 99,25 \\
\hline 3 & 90 & $1.397,54$ & $4.470,40$ & $1.448,57$ & $4.521,43$ & 99,22 & 173 & 4,71 & 37,87 & 4,91 & 38,07 & 98,99 \\
\hline 4 & 38 & $1.287,10$ & $4.359,96$ & $1.408,20$ & $4.481,06$ & 98,34 & 138 & 4,67 & 37,83 & 4,85 & 38,01 & 98,84 \\
\hline 5 & 68 & $1.028,64$ & $4.101,51$ & $1.332,29$ & $4.405,15$ & 96,67 & 52 & 4,65 & 37,81 & 4,81 & 37,97 & 98,74 \\
\hline 6 & 4 & 993,77 & $4.066,63$ & $1.275,87$ & $4.348,73$ & 95,43 & 98 & 4,58 & 37,73 & 4,77 & 37,93 & 98,64 \\
\hline 7 & 94 & 801,79 & $3.874,65$ & $1.208,14$ & $4.281,01$ & 93,95 & 2 & 4,40 & 37,56 & 4,72 & 37,88 & 98,50 \\
\hline 8 & 117 & 789,18 & $3.862,04$ & $1.155,77$ & $4.228,64$ & 92,80 & 100 & 4,36 & 37,52 & 4,67 & 37,83 & 98,38 \\
\hline 9 & 53 & 775,42 & $3.848,28$ & $1.113,51$ & $4.186,37$ & 91,87 & 72 & 4,29 & 37,45 & 4,63 & 37,79 & 98,27 \\
\hline 10 & 71 & 746,55 & $3.819,41$ & $1.076,82$ & $4.149,68$ & 91,07 & 6 & 4,17 & 37,33 & 4,59 & 37,74 & 98,16 \\
\hline 11 & 15 & 725,41 & $3.798,27$ & $1.044,87$ & $4.117,73$ & 90,36 & 65 & 4,03 & 37,19 & 453 & 37,69 & 98,02 \\
\hline 12 & 129 & 717,70 & $3.790,56$ & $1.017,61$ & $4.090,47$ & 89,77 & 165 & 3,96 & 37,12 & 4,49 & 37,65 & 97,90 \\
\hline 13 & 83 & 717,50 & $3.790,36$ & 994,52 & $4.067,38$ & 89,26 & 96 & 3,79 & 36,95 & 4,43 & 37,59 & 97,76 \\
\hline 14 & 93 & 709,91 & $3.782,78$ & 974,19 & $4.047,05$ & 88,81 & 32 & 3,74 & 36,90 & 4,38 & 37,54 & 97,63 \\
\hline 15 & 73 & 701,88 & $3.774,74$ & 956,04 & $4.028,90$ & 88,42 & 171 & 3,64 & 36,80 & 4,33 & 37,49 & 97,50 \\
\hline 16 & 69 & 640,90 & $3.713,76$ & 936,34 & $4.009,20$ & 87,98 & 169 & 3,49 & 36,64 & 4,28 & 37,44 & 97,37 \\
\hline 17 & 41 & 639,76 & $3.712,63$ & 918,90 & $3.991,76$ & 87,60 & 80 & 3,49 & 36,64 & 4,23 & 37,39 & 97,24 \\
\hline 18 & 181 & 589,64 & $3.662,50$ & 900,60 & $3.973,46$ & 87,20 & 1 & 3,41 & 36,57 & 4,19 & 37,35 & 97,13 \\
\hline 19 & 183 & 579,54 & $3.652,40$ & 883,71 & $3.956,57$ & 86,83 & 101 & 3,39 & 36,55 & 4,15 & 37,31 & 97,02 \\
\hline 20 & 86 & 569,12 & $3.641,99$ & 867,98 & $3.940,84$ & 86,48 & 79 & 3,22 & 36,38 & 4,10 & 37,26 & 96,90 \\
\hline 21 & 47 & 565,48 & $3.638,34$ & 853,57 & $3.926,43$ & 86,17 & 89 & 3,14 & 36,30 & 4,06 & 37,21 & 96,78 \\
\hline 22 & 85 & 551,45 & $3.624,31$ & 839,84 & $3.912,70$ & 85,87 & 83 & 3,13 & 36,29 & 4,01 & 37,17 & 96,67 \\
\hline 23 & 119 & 544,23 & $3.617,09$ & 826,99 & $3.899,85$ & 85,58 & 37 & 3,09 & 36,25 & 3,97 & 37,13 & 96,56 \\
\hline 24 & 49 & 532,02 & $3.604,88$ & 814,70 & $3.887,56$ & 85,31 & 87 & 2,93 & 36,09 & 3,93 & 37,09 & 96,45 \\
\hline 25 & 160 & 530,19 & $3.603,05$ & 803,32 & $3.876,18$ & 85,06 & 148 & 2,86 & 36,02 & 3,89 & 37,05 & 96,34 \\
\hline 26 & 40 & 528,54 & $3.601,40$ & 792,75 & $3.865,61$ & 84,83 & 47 & 2,84 & 36,00 & 3,85 & 37,01 & 96,23 \\
\hline 27 & 108 & 517,14 & $3.590,00$ & 782,54 & $3.855,40$ & 84,61 & 7 & 2,81 & 35,96 & 3,81 & 36,97 & 96,13 \\
\hline 28 & 92 & 504,70 & $3.577,56$ & 772,62 & $3.845,48$ & 84,39 & 84 & 2,79 & 35,95 & 3,77 & 36,93 & 96,04 \\
\hline 29 & 70 & 496,94 & $3.569,80$ & 763,11 & $3.835,97$ & 84,18 & 140 & 2,65 & 35,81 & 3,73 & 36,89 & 95,94 \\
\hline 30 & 58 & 488,28 & $3.561,15$ & 753,95 & $3.826,81$ & 83,98 & 51 & 2,56 & 35,71 & 3,69 & 36,85 & 95,84 \\
\hline
\end{tabular}

O método REML/Blup se mostrou muito mais eficiente do que os índices de seleção, tendo selecionado progênies com desempenhos relativos elevados e com ganhos genéticos preditos promissores para a cultura do milho-pipoca. Porém, em geral, as progênies com maior rendimento de grãos não foram aquelas com maior capacidade de expansão (Tabela 3), o que corrobora os dados de Arnhold et al. (2006), os quais concluíram que a associação negativa entre capacidade de expansão e rendimento de grãos interfere na obtenção de ganhos de seleção simultânea quanto às características $\mathrm{RG}$ e $\mathrm{CE}$, na melhoria da população.

\section{Conclusões}

1. Entre os quatro índices de seleção testados, o de Mulamba \& Mock é o mais adequado para a seleção das progênies de irmãos-completos na população UENF 14 de milho-pipoca.

2. O método REML/Blup apresenta os melhores ganhos genéticos preditos, em comparação aos obtidos pelos índices de seleção, e é eficiente para seleção de progênies de irmãos-completos na população UENF 14 de milho-pipoca.

3. As progênies selecionadas com uso do método REML/Blup, para maior rendimento de grãos, não são as mesmas selecionadas para maior capacidade de expansão. 


\section{Agradecimentos}

Ao Conselho Nacional de Desenvolvimento Científico e Tecnológico (CNPq), pelo apoio financeiro.

\section{Referências}

AMARAL JÚNIOR, A.T.; FREITAS JÚNIOR, S.P.; RANGEL, R.M.; PENA, G.F.; RIBEIRO, R.M.; MORAIS, R.C.; SCHUELTER, A.R. Improvement of a popcorn population using selection indexes from a fourth cycle of recurrent selection program carried out in two different environments. Genetics and Molecular Research, v.9, p.340-370, 2010. DOI: 10.4238/vol9-1gmr702.

ARNHOLD, E.; MORA, F.; DEITOS, A. Correlaciones genéticas en familias S4 de maíz (Zea mays). Ciencia e Investigación Agraria, v.33, p.125-131, 2006.

ARNHOLD, E.; MORA, F.; SILVA, R.G.; GOOD-GOD, P.I.V.; RODOVALHO, M.A. Evaluation of top-cross popcorn hybrids using mixed linear model methodology. Chilean Journal of Agricultural Research, v.69, p.46-53, 2009. DOI: 10.4067/ S0718-58392009000100006.

BERILLI, A.P.C.G.; PEREIRA, M.G.; GONCALVES, L.S.A.; CUNHA, K.S. da; RAMOS, H.C.C.; SOUZA FILHO, G.A.; AMARAL JÚNIOR, A.T. do. Use of molecular markers in reciprocal recurrent selection of maize increases heterosis effects. Genetics and Molecular Research, v.10, p.2589-2596, 2011. DOI: 10.4238/2011.October.25.6.

BORGES, V.; FERREIRA, P.V.; SOARES, L.; SANTOS, G.M.; SANTOS, A.M.M. Seleção de clones de batata-doce pelo procedimento REML/BLUP. Acta Scientiarum. Agronomy, v.32, p.643-649, 2010. DOI: 10.4025/actasciagron.v32i4.4837.

CRUZ, C.D. GENES - a software package for analysis in experimental statistics and quantitative genetics. Acta Scientiarum. Agronomy, v.35, p.271-276, 2013. DOI: 10.4025/ actasciagron.v35i3.21251.

CRUZ, C.D.; REGAZZI, A.J.; CARNEIRO, P.C.S. Modelos biométricos aplicados ao melhoramento genético. 3.ed. Viçosa: Ed. da UFV, 2012. 480p.

DAROS, M.; AMARAL JÚNIOR, A.T. do; PEREIRA, M.G.; SANTOS, F.S.; SCAPIM, C.A.; FREITAS JÚNIOR, S.P.; DAHER R.F.; ÁVILA, M.R. Correlações entre caracteres agronômicos em dois ciclos de seleção recorrente em milho-pipoca. Ciência Rural, v.34, p.1389-1394, 2004. DOI: 10.1590/ S0103-84782004000500010.

FANCELLI, A.L.; DOURADO NETO, D. Produção de milho. Guaíba: Agropecuária, 2000. 360p.

FREITAS JÚNIOR, S. de P.; AMARAL JÚNIOR, A.T. do; RANGEL, R.M.; VIANA, A.P. Predição de ganhos genéticos na população de milho-pipoca UNB-2U sob seleção recorrente utilizando-se diferentes índices de seleção. Semina: Ciências Agrárias, v.30, p.803-814, 2009. DOI: 10.5433/1679-0359.2009v3 0n4p803.

GRANATE, M.J.; CRUZ, C.D.; PACHECO, C.A.P. Predição de ganho genético com diferentes índices de seleção no milho-pipoca
CMS-43. Pesquisa Agropecuária Brasileira, v.37, p.1001-1008, 2002. DOI: 10.1590/S0100-204X2002000700014.

HAZEL, L.N. The genetic basis for constructing selection indexes. Genetics, v.28, p.476-490, 1943.

LA GIOIA, D.R. As metodologias de índices de seleção aplicadas ao melhoramento de plantas forrageiras. 2006. 142p. Tese (Doutorado) - Universidade Federal do Rio Grande do Sul, Porto Alegre.

LEVANTAMENTO SISTEMÁTICO DA PRODUÇÃO AGRÍCOLA. Rio de Janeiro: IBGE, v.26, n.1, jan. 2013. 83p.

MIRANDA, G.V.; COIMBRA, R.R.; GODOY, C.L.; SOUZA, L.V.; GUIMARÃES, L.J.M.; MELO, A.V. de. Potencial de melhoramento e divergência genética de cultivares de milho-pipoca. Pesquisa Agropecuária Brasileira, v.38, p.681-688, 2003. DOI: 10.1590/ S0100-204X2003000600003.

MOTERLE, L.M.; BRACCINI, A. de L. e; SCAPIM, C.A.; PINTO, R.J.B.; GONÇALVES, L.S.A.; RODRIGUES, R.; AMARAL JÚNIOR, A.T. do. Combining ability of popcorn lines for seed quality and agronomic traits. Euphytica, v.185, p.337-347, 2011. DOI: 10.1007/s10681-011-0458-2.

MULAMBA, N.N.; MOCK, J.J. Improvement of yield potential of the Eto Blanco maize (Zea mays L.) population by breeding for plant traits. Egyptian Journal of Genetics and Cytology, v.7, p.40-51, 1978.

PEDROZO, C.Â.; BENITES, F.R.G.; BARBOSA, M.H.P.; RESENDE, M.D.V. de; SILVA, F.L. da. Eficiência de índices de seleção utilizando a metodologia REML/BLUP no melhoramento da cana-de-açúcar. Scientia Agraria, v.10, p.31-36, 2009.

PENA, G.F.; AMARAL JÚNIOR, A.T. do; GONÇALVES, L.S.A.; CANDIDO, L.S.; VITTORAZZI, C.; RIBEIRO, R.M.; FREITAS JÚNIOR, S.P. Stability and adaptability of popcorn genotypes in the State of Rio de Janeiro, Brazil. Genetics and Molecular Research, v.11, p.3042-3050, 2012. DOI: 10.4238/2012.August.31.1.

PEREIRA, M.G.E.; AMARAL JÚNIOR, A.T. Estimation of genetic components in popcorn based on the nested design. Crop Breeding and Applied Biotechnology, v.1, p.3-10, 2001. DOI: 10.13082/1984-7033.v01n01a01.

PEŠEK, J.; BAKER, R.J. Desired improvement in relation to selection indices. Canadian Journal of Plant Science, v.49, p.803-804, 1969. DOI: 10.4141/cjps69-137.

RANGEL, R.M.; AMARAL JÚNIOR, A.T. do; GONÇALVES, L.S.; FREITAS JÚNIOR, S. de P.; CANDIDO, L.S. Análise biométrica de ganhos por seleção em população de milho-pipoca de quinto ciclo de seleção recorrente. Revista Ciência Agronômica, v.42, p.473-481, 2011. DOI: 10.1590/S1806-66902011000200029.

RANGEL, R.M.; AMARAL JÚNIOR, A.T.; SCAPIM, C.A.; FREITAS JÚNIOR, S.P.; PEREIRA, M.G. Genetic parameters in parents and hybrids of circulant diallel in popcorn. Genetics and Molecular Research, v.7, p.1020-1030, 2008. DOI: 10.4238/ vol7-4gmr502.

RESENDE, M.D.V. de; STURION, J.A. Análise genética de dados com dependência espacial e temporal no melhoramento de plantas perenes via modelos geoestatísticos e de séries 
temporais empregando REML/BLUP ao nível individual. Colombo: Embrapa Florestas, 2001. 80p. (Embrapa Florestas. Documentos, 65).

RIBEIRO, R.M.; AMARAL JÚNIOR, A.T. do; GONÇALVES, L.S.A.; CANDIDO, L.S.; SILVA, T.R.; PENA, G.F. Genetic progress in the UNB-2U population of popcorn under recurrent selection in Rio de Janeiro. Genetics and Molecular Research, v.11, p.1417-1423, 2012. DOI: 10.4238/2012. May.15.12.

RODRIGUES, W.P.; VIEIRA, H.D.; BARBOSA, D.H.; SOUZA FILHO, G.R.; CANDIDO, L.S. Adaptability and genotypic stability of Coffea arabica genotypes based on REML/BLUP analysis in Rio de Janeiro State, Brazil. Genetics and Molecular Research, v.12, p. 2391-2399, 2013. DOI: 10.4238/2013. July.15.2.

SANTOS, F.S.; AMARAL JÚNIOR, A.T. do; FREITAS JÚNIOR, S. de P.; RANGEL, R.M.; SCAPIM, C.A.; MORA, F.M. Genetic gain prediction of the third recurrent selection cycle in a popcorn population. Acta Scientiarum. Agronomy, v.30, p.651-655, 2008. DOI: 10.4025/actasciagron.v30i5.3174.
SILVA, T.R. da C.; AMARAL JÚNIOR, A.T. do; GONÇALVES, L.S.A.; CANDIDO, L.S.; VITORAZZI. C.; SCAPIM, C.A. Agronomic performance of popcorn genotypes in Northern and Northwestern Rio de Janeiro State. Acta Scientiarum. Agronomy, v.35, p.57-63, 2013. DOI: 10.4025/ actasciagron.v35i1.15694.

SMITH, H.F. A discriminant function for plant selection. Annals of Eugenics, v.7, p.240-250, 1936. DOI: 10.1111/j.1469-1809.1936. tb02143.x.

VILARINHO, A.A.; VIANA, J.M.S.; SANTOS, J.F. dos; CÂMARA, T.M.M. Eficiência da seleção de progênies S1 e S2 de milho-pipoca, visando à produção de linhagens. Bragantia, v.6, p.9-17, 2003. DOI: 10.1590/S0006-87052003000100002.

VITTORAZZI, C.; AMARAL JÚNIOR, A.T. do; GONÇALVES, L.S.A.; CANDIDO, L.S.; SILVA, T.R.C. Selecting pre-cultivars of popcorn maize based on nonparametric indices. Revista Ciência Agronômica, v.44, p.356-362, 2013. DOI: 10.1590/S1806-66902013000200019.

WILLIAMS, J.S. The evaluation of a selection index. Biometrics, v.18, p.375-393, 1962. DOI: $10.2307 / 2527479$.

Recebido em 5 de setembro de 2013 e aprovado em 30 de outubro de 2013 